\title{
Corrigendum: Development of a Machine Learning Model for Optimal Applicator Selection in High-Dose- Rate Cervical Brachytherapy
}

\author{
Kailyn Stenhouse ${ }^{1,2 *}$, Michael Roumeliotis ${ }^{1,2,3}$, Philip Ciunkiewicz ${ }^{4}$, Robyn Banerjee ${ }^{3,5}$, \\ Svetlana Yanushkevich ${ }^{6}$ and Philip McGeachy ${ }^{1,2,3}$ \\ ${ }^{1}$ Department of Physics and Astronomy, University of Calgary, Calgary, AB, Canada, ${ }^{2}$ Department of Medical Physics, Tom \\ Baker Cancer Centre, Calgary, AB, Canada, ${ }^{3}$ Department of Oncology, University of Calgary, Calgary, AB, Canada, \\ ${ }^{4}$ Department of Biomedical Engineering, University of Calgary, Calgary, AB, Canada, ${ }^{5}$ Department of Radiation Oncology, \\ Tom Baker Cancer Centre, Calgary, AB, Canada, ${ }^{6}$ Department of Electrical and Computer Engineering, University of \\ Calgary, Calgary, AB, Canada
}

Keywords: gynecologic brachytherapy, intracavitary brachytherapy, high-dose-rate brachytherapy, radiation oncology, machine learning, decision-support tools

\section{OPEN ACCESS}

Approved by:

Frontiers Editorial Office

Frontiers Media SA, Switzerland

${ }^{*}$ Correspondence:

Kailyn Stenhouse

kailyn.stenhouse@gmail.com

Specialty section:

This article was submitted to

Radiation Oncology,

a section of the journal

Frontiers in Oncology

Received: 24 June 2021 Accepted: 25 June 2021 Published: 06 July 2021

Citation:

Stenhouse K, Roumeliotis $M$

Ciunkiewicz $P$, Banerjee $R$, Yanushkevich $S$ and McGeachy $P$ (2021) Corrigendum: Development

of a Machine Learning Model for Optimal Applicator Selection in HighDose-Rate Cervical Brachytherapy.

Front. Oncol. 11:730375.

doi: 10.3389/fonc.2021.730375

\section{A Corrigendum on}

Development of a Machine Learning Model for Optimal Applicator Selection in High-DoseRate Cervical Brachytherapy

By Stenhouse K, Roumeliotis M, Ciunkiewicz P, Banerjee R, Yanushkevich S and McGeachy P (2021). Front. Oncol. 11:611437. doi: 10.3389/fonc.2021.611437

Philip Ciunkiewicz was not included as an author in the published article. The corrected Author Contributions Statement appears below.

KS and PC collected data, extracted features, deployed and evaluated machine learning algorithms, interpreted and visualized results, and drafted the manuscript. MR and PM conceptualized the project and participated in the study design, analysis and interpretation of results, and drafting of the manuscript. RB and SY provided expert guidance throughout the study and interpretation of results. All authors contributed to the article and approved the submitted version

In the published article, there was an error regarding the affiliation for Philip Ciunkiewicz. They should have ${ }^{4}$ Department of Biomedical Engineering, University of Calgary, Calgary, AB, Canada.

The authors apologize for these errors and state that this does not change the scientific conclusions of the article in any way. The original article has been updated

Copyright (c) 2021 Stenhouse, Roumeliotis, Ciunkiewicz, Banerjee, Yanushkevich and McGeachy. This is an open-access article distributed under the terms of the Creative Commons Attribution License (CC BY). The use, distribution or reproduction in other forums is permitted, provided the original author(s) and the copyright owner(s) are credited and that the original publication in this journal is cited, in accordance with accepted academic practice. No use, distribution or reproduction is permitted which does not comply with these terms. 